\title{
A visibilidade ambiental em perspectiva sociológica: estudo comparado Brasil-Portugal
}

ANTONIO TEKKERA DE BARROS"

\section{Resumo}

Análise sobre a produção social da visibilidade das temáticas ambientais no Brasil e em Portugal, no contexto recente, pelo ângulo da mediatização, com destaque para o papel da televisão. O objetivo é examinar como foram construídos os arranjos analíticos sociomediáticos a partir do agendamento e tematização ambiental, com base nas seguintes indagações: (a) quais as questões socioambientais postas em relevo pelos media nos dois países? (b) como se dá a articulação entre estudos mediáticos focados na agenda ambiental e a perspectiva das ciências sociais? (c) que atores sociais são privilegiados por esses estudos? (d) como os arranjos discursivos desses atores são postos em evidência pelos media? Estudo realizado com base em pesquisa bibliográfica, análise documental e revisão sistemática de estudos acadêmicos sobre mediatização ambiental, história das ideias ecológicas, com foco nas convergências entre sociologia da comunicação e sociologia ambiental. As conclusões destacam o caráter ambíguo da mediatização, como parte da lógica dos pacotes interpretativos que guiam a opinião pública.

Palavras-chave: Mediatização do ambiente. Sociologia do ambiente. Media e ambiente. Cultura ambiental. Sociologia da Comunicação.

\footnotetext{
* Doutor em Sociologia. Docente e Pesquisador do Programa de Mestrado em Ciência Política do Centro de Formação Política da Câmara dos Deputados (Brasil).E-mail: antonibarros@gmail.com
} 


\section{The environmental visibility from a sociological perspective: a Brazil-Portugal comparative study}

\section{Abstract}

This article deals with the analysis of the social production of public image of environmental issues in Brazil and Portugal in recent contexts. For this purpose the paper takes the perspective of the media coverage, highlighting the role of television. The aim is to examine how the socio-analytic arrangements were constructed by the media entities, from setting the agenda and the subject of environment, based on the following questions: (a) what are the environmental issues highlighted by the media in both countries? (b) how do the media studies focused on the environmental agenda relate to the analytical perspective of the social sciences? (c) what social actors are favored in these studies? (d) how are the discursive arrangements of these actors exhibited by the media? The study was based on literature review, document analysis and systematic review of academic studies on environmental mediatization and history of ecological ideas, focusing on the convergence of sociology of communication and environmental sociology. The conclusions reveal the ambiguous nature of media coverage, as part of the logic of interpretive templates that guide public opinion.

Keywords: Environment mediatization. Environmental sociology. Media and environment. Environmental Culture. Communication sociology.

\section{Introdução}

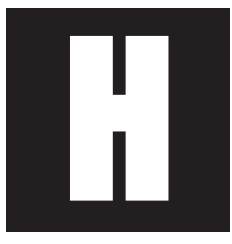

istoricamente, os media exerceram papel expressivo na divulgação da agenda ambiental, um fenômeno que adquiriu projeção internacional. Inicialmente, a ecologia era tratada de forma episódica e fragmentada, mas, com o passar do tempo, tornou-se um supertema, ao romper a lógica de assunto eventual da agenda mediática para tornar-se problemática com abordagem continuada e recorrente. Atualmente, as pautas sobre ambiente cobrem assuntos diretamente relacionados ao cotidiano do cida- 
dão, como a coleta seletiva de lixo, o desperdício de água, a redução do consumo de energia elétrica nos domicílios, o uso de combustíveis fósseis nos automóveis etc. É a inserção social da agenda ambiental nas relações sociais do cotidiano. A partir desse cenário mais amplo, este artigo tem como foco temático a construção social da mediatização das questões socioambientais no Brasil e em Portugal. É oportuno ressaltar que há vários paralelos relativos à formação dos movimentos em defesa do ambiente e ao processo de mediatização das questões socioambientais nos dois países, especialmente no que se refere à abordagem dos media sobre assuntos como desenvolvimento sustentável, análise de impactos socioambientais e aquecimento global (Barros e Sousa, 2010).

A premissa que orienta o estudo é o de que essa a inserção do ambiente nas pautas dos media deve ser compreendida como um fenômeno social e culturalmente construído, ou seja, resultante das relações entre os diferentes sujeitos e atores sociais e políticos - que atuam como fontes de informação -, representados por múltiplos polos de interesse, tais como o Estado, a sociedade civil, os movimentos sociais e a comunidade científica. Tal ideia encontra respaldo no pressuposto sociológico de que as necessidades e os valores sociais são definidos e redefinidos de acordo com a racionalidade da dinâmica sociocultural, marcada pela vontade e o julgamento que comandam as motivações para o agir na esfera pública, consoante com as diferenciações relativas às distintas épocas históricas, sociedades, classes e grupos sociais. Afinal, as necessidades sociais não são homogêneas, nem fixas e nem seguem leis pré-estabelecidas. Ao contrário, são diversificadas, em decorrência da pluralidade de sujeitos que as expressam e são também criadas e recriadas em função inclusive dos avanços tecnológicos, dos progressos no campo político-cultural e dos arranjos simbólicos e institucionais resultantes dessa dinâmica interacional (Figueiredo, 1989). 
O texto apresenta como objetivo examinar como foram construídos os arranjos analíticos sociomediáticos a partir do agendamento e tematização ambiental, com base nas seguintes indagações: (a) quais as questões socioambientais postas em relevo pelos media nos dois países? (b) como se dá a articulação entre estudos mediáticos focados na agenda ambiental e a perspectiva analítica das ciências sociais? (c) que atores sociais são privilegiados por esses estudos? (d) como os arranjos discursivos desses atores são postos em evidência pelo enquadramento mediático?

Com efeito, o discurso dos media sobre ambiente não deve ser entendido como produção autônoma, em vista dessa configuração relacional complexa e multifacetada. Além da diversidade de atores, os media passaram a destacar diferentes aspectos relacionados aos temas ambientais (naturais, políticos, econômicos, culturais, ideológicos). Trata-se de um discurso condicionado por múltiplos fatores, segundo a perspectiva sociológica da teoria multifactorial da notícia (Sousa, 2000).

O recorte cronológico do estudo compreende o período de 1990 a 2007. A escolha do período teve como base levantamento preliminar, no qual constatou-se que não há registro de estudos sobre mediatização ambiental na década de 1970 nos dois países, com poucos e assistemáticos estudos na década de 1980 (Barros e Sousa, 2010), mas com uma profusão de análises acadêmicas a partir da década de 1990. Inicialmente os estudos se limitavam ao campo das ciências da natureza. A partir da metade da década de 1980 é que as pesquisas sobre mediatização ambiental começaram a ser publicadas, tanto no Brasil como em Portugal, mas ainda de forma tímida e esparsa. A profusão de estudos na década de 1990 foi impulsionada pela Cúpula da Terra (Rio 92). Outro pico de produção de pesquisas sobre mediatização ambiental ocorreu com a assinatura do Protocolo de Kyoto (1997) e a divulgação dos relatórios do Painel Intergovernamental sobre Mudanças Climáticas (2003 a 2007). Tudo isso explica 
a concentração de publicações nas décadas de 1990 e 2000, pelo menos até o momento de finalização da pesquisa.

Antes da análise, o texto apresenta um panorama sobre a visibilidade ambiental produzida pelos media, além de uma descrição dos procedimentos metodológicos utilizados.

\section{Visibilidade e diversificação dos atores socioambientais}

Um dos pontos de maior tensão na relação entre os atores socioambientais é a disputa pelo controle da visibilidade mediática (Barros e Sousa, 2010). Cada segmento tenta estabelecer estratégias de atuação para capitalizar seus discursos, ideias e a ações no espaço público de aparência e visibilidade social dos media, a fim de conseguirem o máximo de eficácia política de suas ações, do ponto de vista da captação da atenção e interesse dos públicos. Nesse cenário de múltiplos focos de interesse, é necessário ressaltar ainda a diversidade de atores e suas lógicas de ação, embora não seja possível aprofundar tal aspecto em função da exiguidade de espaço. Contudo, é oportuno destacar o papel dos movimentos sociais nos anos 1960-80, a atuação e militância dos partidos verdes, o impacto das conferências globais sobre meio-ambiente e desenvolvimento dos anos 1970 até agora, a atuação da comunidade científica em diversas áreas e diferentes países, principalmente no que se refere aos alertas sobre mudanças climáticas. ${ }^{1}$

Com a repercussão e os desdobramentos da Cúpula da Terra (Rio 92), o socioambientalismo consolidou-se como um fenômeno mediatizado. A mediatização, segundo Braga (2006a; 2006b), tornou-se um processo social

\footnotetext{
${ }^{1}$ Para uma contextualização mais ampla sobre a pluralidade e as especificidades desses atores, consultar Alonso e Costa, 200; Barros, 1996; Barros e Sousa, 2010, Born, 2005; Viola e Leis, 1995.
} 
de referência, no sentido de que os processos sociais passam a se desenvolver (inteira ou parcialmente) segundo as lógicas dos media, como a política, o entretenimento e a aprendizagem. A mediatização tornou-se responsável pelo delineamento dos temas na agenda pública, além do enquadramento, do ciclo de atenção dos temas (com maior ou menor tempo de permanência na agenda). Além disso, grande parte do conhecimento e da experiência dos públicos no que se refere a assuntos ambientais passa necessariamente pelo enquadramento dos media, que se tornaram fonte primordial de informação, especialmente a televisão. Os media traduzem e formam as percepções que as pessoas não experimentam diretamente (Schmidt, 2003, p.69). Entretanto, é necessário ressaltar que a adesão da opinião pública não depende apenas dos media. A eficácia da popularização produzida pelos media depende de um conjunto articulado de fatores, tais como a ressonância prévia de um assunto, as referências que ele desencadeie (nos jornalistas e no público), a identidade cultural de quem o recebe, além da formação e informação que já existia previamente a respeito de um assunto (Schmidt, 2003, p.78).

Aqui cabe uma ressalva, a qual servirá para esclarecer um ponto relevante do ponto de vista da compreensão do escopo mais abrangente do artigo. Trata-se da relação entre os media e os atores socioambientais. Apesar do foco do texto recair sobre a mediação da mediação, ou seja, os estudos analíticos do campo das ciências sociais sobre os media, é necessário ressaltar que, como agentes mediadores, os próprios media também devem ser compreendidos como atores socioambientais. Afinal, os media também são constituídos por pessoas, suas ações, táticas, estratégias e relações de poder. Como empresas, os veículos de mídia também articulam-se às lógicas empresariais dos demais veículos e de outros setores, como os anunciantes. Em suma, isso mostra que a mediação ocorre em um contexto de múltiplas permeabilidades, no qual há muitos interesses em jogo. 


\section{Descrição da pesquisa e da metodologia}

O estudo foi realizado com base em pesquisa bibliográfica e revisão sistemática de estudos acadêmicos sobre mediatização ambiental, história das ideias ecológicas, sociologia da comunicação e as ciências sociais do ambiente. A técnica de meta-análise ou revisão sistemática consiste no exame minucioso de pesquisas já realizadas sobre um tema determinado, a fim de organizar o conhecimento produzido, comparar tendências, metodologias e produzir inferências (Clarke, 2001). De forma mais pormenorizada, a meta-análise é um método de investigação baseado em dados e conclusões obtidos em pesquisas e estudos executados por outros pesquisadores, que vem sendo utilizado de modo crescente nos últimos anos. Mas não consiste em mera revisão bibliográfica ou de literatura especializada, uma vez que os estudos meta-analíticos exigem procedimentos de seleção, codificação, filtragem de dados, sistematização das informações e gestão da base bibliográfica resultante (Aguiar, 2011, p.3).

Nessa perspectiva, a meta-análise foi aplicada com base na concepção operacional de obras-síntese, ou seja, publicações expressivas e representativas em termos de abordagens, abrangência temática, ferramentas metodológicas e referencial teórico utilizado. Foram selecionadas dez obras emblemáticas e relevantes (cinco de cada país), de modo a incluir no corpus da pesquisa obras-síntese referentes às diversas fases do período histórico estudado ${ }^{2}$. No âmbito deste trabalho, entende por obra-síntese uma pesquisa que reúne um capital de conhecimentos que sintetiza as principais ideias, paradigmas e procedimentos metodológicos referentes a uma área de conhecimento em um determinado período his-

${ }^{2} \mathrm{O}$ corpus da pesquisa é composto pelos seguintes estudos: Brasil: (1) Dencker, A. F. \& Kunsch, M. M. K. (1996); (2) Oliveira, M.T.C. (1991); (3) Costa, L. M. (2006); (4) Motta, L. G. Et Al. (2006); (5) Trigueiro, A. (2005). Portugal: (6) Schmidt, L. (2003); (7) Garcia, R (2004); (8) Pereira Rosa, G. (2006); (9) Vieira, P. A. (2006); (10) Freitas, H. De S. (2007). 
tórico. Assim, uma pesquisa pode ser representativa sem necessariamente incluir todos os estudos realizados em uma década, por exemplo, visto que os conteúdos se repetem. O pressuposto, portanto, é que uma única obra-síntese pode servir de referência para a análise e compreensão dos conteúdos de uma área de conhecimentos no decorrer de um período específico, como um decênio ou um quinquênio.

A seleção das obras-síntese se deu com base em critérios delineados por pesquisa bibliográfica prévia, com levantamento da produção de cada país, por década, mediante registro em relatórios bibliográficos detaIhados. Para ser incluída na categoria de obra-síntese, levou-se em conta a abrangência da pesquisa, o período histórico compreendido, as teorias de base, o escopo da análise empírica ou a consistência teórica e analítica. Outro critério considerado foi o reconhecimento e legitimidade desses estudos pela comunidade acadêmica no Brasil e em Portugal, a partir do levantamento dos textos mais citados em comunicações apresentadas em congressos científicos, artigos de periódicos, capítulos de livros e demais publicações relacionadas ao tema no período compreendido pela pesquisa, considerando o foco sociomediático da abordagem.

Cabe ressaltar que a análise não se limitou a essas dez obras selecionadas. Esse corpus constitui a referência principal, o que não significa a exclusão de outras obras. De forma complementar, foram utilizadas dezenas de outras publicações, com o intuito de complementar as informações e enriquecer a pesquisa. O material complementar ao corpus principal é composto por textos de periódicos, de portais acadêmicos, comunicações científicas apresentadas em eventos, além de livros e capítulos de livros que apresentam temáticas relacionadas ao tema analisado. Em alguns casos, foram referenciados estudos nos quais os assuntos relacionados ao recorte temático não aparecia em primeiro plano. Entretanto, a leitura revelava dados e informações de interesse para a contextualização da 
pesquisa ou para a complementação de explicações expostas nas obras que compunham o corpus de análise.

Em termos de procedimentos operacionais da pesquisa cabe ressaltar ainda que, apesar das convergências teóricas e metodológicas, o modus operandi dos estudos que integram o corpus é peculiar à cultura acadêmica de cada país, o que dificultou uma padronização, sobretudo do ponto de vista da organização e nomeação das categorias temáticas para a realização da meta-análise. A classificação utilizada pelos pesquisadores brasileiros, apesar de abranger conteúdos similares, é diferente dos procedimentos empregados pelos pesquisadores portugueses. Diante da impossibilidade de definição de categorias homogêneas, optamos pela elaboração de um novo padrão de organização temática ou recategorização. Para isso, seguimos o princípio da fidelidade ao conteúdo temático (Bardin, 1977), mas adotamos outra nomenclatura, capaz de albergar os assuntos contidos pelas pesquisas analisadas. Esse procedimento é compatível com a meta-análise. Consiste em um recurso metodológico híbrido de segunda geração, ou seja, é formulada a partir de dados primários ou secundários já tratados analiticamente (primeira geração). A recategorização, portanto, serve-se do conteúdo temático, mas reúne categorias nomeadas aparentemente de forma distinta, mas com afinidade de conteúdo (Barros e Sousa, 2010).

\section{Os estudos analisados e as questões socioambientais mais relevantes}

Os problemas investigados são diversificados, o que impede um mapeamento completo. Seguimos, portanto, a lógica da recategorização, conforme foi explicado no item sobre a metodologia. Com base nesse procedimento sistemático, optamos por um levantamento de seis questões, as quais resultaram de uma minuciosa seleção, com base nos seguintes critérios: (a) tema central de estudos publicados (livros ou capítulos, por exemplo); (b) 
delimitação clara do problema de pesquisa pelos autores; (c) desenvolvimento e consistência analítica; (d) coerência e profundidade da pesquisa; (e) relevância acadêmica do problema formulado. Algumas das questões são pertinentes a estudos realizados no Brasil e em Portugal, mas há itens que se restringem a um país. No corpo da análise, esses casos são identificados. A sistematização dos problemas investigados foi realizada de acordo com o conteúdo e não com a origem geográfica dos estudos. A seguir, apresentamos os itens do inventário realizado, em forma de questões.

\subsection{Porque a TV se estabeleceu como o meio} de comunicação mais importante em termos ambientais?

Considerando o escopo analítico deste artigo, ou seja, a análise da visibilidade ambiental pelo enquadramento sociomediático com destaque para a mediação televisiva, este tópico assume especial relevância ao se considerar o contexto cultural dos dois países (Brasil e Portugal), uma vez que em ambos a TV assumiu primazia da divulgação das temáticas ecológicas, conforme já foi assinalado anteriormente.

No caso brasileiro, há um extenso percurso de contextualização acerca dos antecedentes da mediatização, os quais são diversificados e incluem as revistas ilustradas, o cinema e as telenovelas ${ }^{3}$. A grande audiência das telenovelas contribuiu para torná-las um produto televiso por

\footnotetext{
${ }^{3}$ Sodré (1983) identifica nas revistas ilustradas um dos relevantes antecedentes da mediatização do ambiente no Brasil, especialmente em função de grandes reportagens sobre a vida de povos indígenas e de curiosidades sobre a fauna e a flora amazônicas. Entre essas revistas, o autor destaca O Cruzeiro (1928-1975), Manchete (1952-2000) e Realidade (1966-1968). Patrocinada pelos Diários Associados de Assis Chateaubriand, O Cruzeiro é considerada a principal revista ilustrada brasileira do século XX. Já a revista Manchete, inspirada na parisiense Paris Match, foi uma das líderes no mercado editorial de 1952 a 2000, com destaque para o fotojornalismo. A revista Realidade, inspirada no modelo americano do new journalism, circulou apenas por três anos, pois foi fechada pelo Ato Institucional n.5 (editado em 1968), mas tornou-se referência em termos de jornalismo ilustrado no Brasil, com impactantes fotorreportagens sobre a Amazônia.
} 
excelência e consolidar a TV como veículo de maior alcance de público. As produções de época foram decisivas para inserir a paisagem do campo no repertório televisivo. Os cenários rurais das produções de época remetem aos tempos de opulência da casa-grande, das fazendas de café e dos engenhos de cana-de-açúcar. O principal objeto material da mediatização é o próprio cenário campesino, com suas paisagens que se tornam ainda mais belas pelo primoroso tratamento estético e fotográfico. O ambiente rural é representado sem as dores e o sofrimento do trabalho e do labor. Com o passar do tempo, as telenovelas abriram espaço para os conteúdos jornalísticos. Assim, a partir da década de 1980, foram criados vários programas televisivos e levados ao público, os quais apresentavam conteúdo ecológico (Barros e Sousa, 2010).

Em suma, a hegemonia mediática da televisão em termos de ambiente é um fenômeno comum tanto em Portugal como no Brasil. No âmbito dos estudos portugueses, sobressai o livro de Luísa Schmidt (2003) sobre o triunfo mediático da TV na sociedade portuguesa, na qual a cultura pública ou opinião pública significam muito aquilo que dá na televisão (Schmidt, 2003, p.17). Como explica a autora, o caso português é emblemático da força da televisão:

A função socializadora da televisão reforçou-se pela sua posição-chave na ocupação dos tempos livres. A tradição de uma sociedade iletrada na qual a imprensa sempre penetrou dificilmente, a falta de alternativas de lazer para grande da população, bem como a sofisticação de seus recursos tecnológicos e o próprio ambiente comunicacional envolvente que a televisão cria, são fatores que têm contribuído para o seu impacto público. (Schmidt, 2003, p.24).

A autora destaca ainda o poder da televisão para chamar atenção para problemas ambientais globais ou locais, ao considerar que a maior parte da população não teria qualquer imagem nem desenvolveria qualquer julgamento sobre a situação de espécies ameaçadas se não fosse a 
mediatização televisiva. A Rádio e Televisão Portuguesa (RTP), conforme a análise da autora, tornou-se "um grande espelho da realidade social" em Portugal, ainda que distorcido, fragmentado e associado ao estereótipo negativo de que a TV empobrece a cultura. Devido a seu poder de penetração e de sedução, a TV continua a ser uma das principais fontes de informação e de representações sobre ambiente em Portugal (e no Brasil).

4.2 Que razões explicam a aproximação entre estudos mediáticos, ambiente e Ciências Sociais?

Existe um paralelismo entre a emergência do ambientalismo e da sociologia do ambiente, como analisou Luísa Schmidt, uma vez que o olhar dos cientistas sociais, em certa medida, foi despertado pela própria mediatização (1999). Por outro lado, o estudo do enquadramento mediático também está diretamente relacionado com o desenvolvimento das ciências sociais, que passaram a se dedicar ao exame dos efeitos sociais da atuação dos media. Assim, é possível deduzir que existe uma triangulação teórica e empírica entre ambientalismo, ciências sociais e estudos de comunicação. Esse pressuposto é reforçado por Schmidt (2003) e Pereira Rosa (2006).

A primeira destaca que o próprio conceito de ambiente pressupõe uma coerência holística que faz dele mais uma vertente dos processos de globalização da sociedade moderna (Schmidt, 2003, p.393). O segundo autor complementa que as clássicas discussões entre o bem natural e o bem humano acompanharam toda a revolução industrial e foram marcando os limites da invasão técnica sobre um mundo prístino e até então equilibrado (Pereira Rosa, 2006, p.7). Assim, prossegue Pereira Rosa (2006), o ambiente tornou-se um tema incontornável nas sociedades ocidentais contemporâneas, na medida em que produz ampla simbologia, movimenta adeptos e detratores e produz árduas batalhas pela legitimidade de cada ponto de vista (Pereira Rosa, 2006, p.8). 
No Brasil, a análise de Ferreira (2006) apresenta desenho similar às pesquisas supracitadas, com o diferencial de aprofundar os aspectos ideológicos dessa complexa relação, com as polêmicas entre os ecologistas radicais e os moderados. Além disso, a autora ressalta:

A sociologia ambiental emergiu a reboque dos movimentos de contestação social surgidos no início dos anos de 1960 (...) O nascimento do movimento na década de 1960 surpreendeu os sociólogos, que naquele momento não dispunham de um corpo teórico ou tradição empírica, que os guiasse em direção ao entendimento da relação entre sociedade e natureza (Ferreira, 2006 p.15).

A atenção de cientistas sociais ao tema foi reforçada pela convergência de interesses de vários segmentos sociais, como movimentos sociais, setores empresariais, organismos internacionais e instituições governamentais. Logo, tornou-se evidente que a questão ambiental não era apenas mais um modismo passageiro, nem uma dramatização de militantes ou cientistas radicais (Ferreira, 2006, p.15). Portanto, a sociologia ambiental assume então uma posição significativa para estudar as divergências e conflitos sobre a natureza (...) e as causas e a extensão dos problemas ambientais entre os diversos atores envolvidos (Ferreira, 2006, p.15).

No âmbito de um processo de revisão teórica e metodológica do campo das Ciências Sociais, a partir da década de 1980, amplia-se o interesse acerca dos fundamentos epistemológicos de uma nova área: as Ciências Sociais do Ambiente, entendidas como um novo domínio inter e transdisciplinar (Alonso; Costa, 2000). As primeiras iniciativas situamse no âmbito da pesquisa ecológico-político, ou seja, uma tentativa de compreender o contexto que propiciou a formação do ambientalismo, bem como a instituição de suas estratégias, procedimentos e protocolos formais. A confluência da Sociologia e da Ciência Política foi relevante nesse processo, gerando contribuições teóricas expressivas. Partia-se do 
pressuposto de que para se compreender a crise ecológica global seria necessário, antes, refletir à luz dos princípios que regem a organização e o funcionamento do sistema sócio-político contemporâneo. A crise ambiental, nesta perspectiva, era concebida como uma crise da forma de ocupação humana do planeta terra, devendo ser interpretada, portanto, como parte de um horizonte mais amplo, ou seja, a crise dos fundamentos da vida política e social (Leis, 1995).

Pereira Rosa explica que o jornalismo, como agente da produção social da realidade, resultante da negociação entre diversos atores, reflete as dinâmicas do contexto social, visto que se trata de uma produção de sentidos sobre o presente e carrega os conflitos e as forças de ação e reação existentes entre os diversos campos sociais. O próprio jornalismo constitui uma arena de disputas de atenção e de credibilidade, na qual a notícia deixa de ser concebida como espelho da realidade e passa a ser vista como resultante de processo sujeito a cargas ideológicas e interveniências subjetivas. Afinal,

Para perceber as notícias, é essencial perceber a sua dimensão cultural - os valores intrínsecos que atravessam lateralmente a comunidade jornalística e que expressam a cultura em que o grupo está inserido, as normas profissionais a que responde e suas as rotinas de cada jornal (Pereira Rosa, 2006, p.21).

Essa concepção remete à teoria multifactorial da notícia (Sousa, 2000), segundo a qual o agendamento do noticiário ambiental luso-brasileiro recebe interferências de múltiplos fatores, em função do contexto, dos organismos internacionais (ONU e Clube de Roma), das organizações não governamentais, das universidades e dos partidos políticos. Em suma, a teoria multifatorial da notícia permite estudar a relação de um fenômeno social com um conjunto de fatores sociais, políticos, históricos, ideológicos. 
4.3 Qual a contribuição dos media para o esclarecimento público a respeito dos temas socioambientais?

Essa questão faz parte de uma análise empírica acerca de como a imprensa brasileira se reportou aos alimentos geneticamente modificados - ou produtos transgênicos (Motta et al., 2006). Trata-se de uma pesquisa pontual, mas que contribui para a compreensão da indagação posta, em termos mais abrangentes. Os estudiosos apresentam as seguintes perguntas específicas: (a) até que ponto a mídia faz uma avaliação conceitual e contextual das questões novas e polêmicas que interessam à sociedade? (b) os diversos grupos e perspectivas são contemplados na divulgação de temas polêmicos? (c) o jornalismo oferece uma cobertura equilibrada, em que todas as opiniões são igualmente representadas?

Como explicam Motta et al. (2006, p. 34-36), as conclusões indicam uma cobertura pouco qualificada, restrita a interesses econômicos específicos, pouco diversificada e nada pluralista (Motta et al., 2006, p.34). Em relação aos alimentos transgênicos, conforme a explicação dos pesquisadores citados, a mídia desprezou os aspectos conceituais, o que na avaliação dos autores do estudo, constituiu falha na abordagem do tema, visto que se tratava de assunto de alta complexidade, o qual deveria ter sido didaticamente explicado. Além disso, poucas notícias fizeram uma contextualização do debate sobre os transgênicos, ou se limitaram a fazer uma contextualização demasiadamente simples (Motta et al., 2006, p.35).

Outra conclusão do estudo mencionado é que a agenda da imprensa sobre transgênicos orientou-se para os acontecimentos políticos institucionais, político-partidários ou jurídicos, principalmente para os aspectos relacionados à aprovação da Lei de Biossegurança. O número de notícias sobre o tema aumentou quando se aproximou a votação da Lei no Congresso Nacional, revelando que a mídia está viciada em cobrir 
as instituições e seus representantes muito mais do que a sociedade civil, que participou ativamente do debate tanto no próprio Congresso como fora dele (Motta et al., 2006, p.35). Essa tendência indica que a mídia brasileira parece não ter o hábito de ouvir a sociedade civil, ou porque isso é mais difícil ou porque o Governo e os políticos estão mais acessíveis. De uma maneira ou de outra, a mídia parece comodista e negligente em suas coberturas (Motta et al., 2006, p.35).

Em suma, o enquadramento dos media negligenciou a sociedade civil, que esteve ativa durante o ano de 2004, na defesa de pontos de vista contrários ou a favor dos transgênicos. O noticiário concentrou-se predominantemente nas fontes oficiais, especialmente nos órgãos do Governo Federal. Eles foram, disparadamente, as fontes mais ouvidas na produção das matérias jornalísticas. Ao contrário, organizações não-governamentais e movimentos sociais diversos estiveram ativos na defesa de seus pontos de vista, mas menos de 5\% das matérias mencionaram as ações e opiniões desses organismos da sociedade civil (Motta et al., 2006, p.35).

Apesar de se tratar de um estudo específico, as conclusões apontam para uma tendência dominante na lógica da mediatização ambiental. Portanto, as inferências são aplicáveis a outros casos também.

4.4 Como se deu a evolução de uma opinião pública voltada para as questões ambientais e o desenvolvimento sustentável?

Esse tópico é investigado por Crespo (2005), em estudo que apresenta uma série histórica de pesquisas de opinião sobre o que os brasileiros pensam a respeito do ambiente. O texto mostra a evolução dos conceitos oriundos da opinião pública, a partir da preocupação com a poluição industrial e as consequências dela na saúde humana até a diversificação e a globalização da agenda verde, com a Conferência do Rio. Crespo destaca que, apesar dessa diversificação e da relativa ampliação 
da consciência ecológica, os brasileiros ainda associam ecologia a medidas que deveriam ser tomadas exclusivamente pelo Governo e práticas a serem adotadas pelas grandes indústrias poluidoras. Isso significa que a preservação do ambiente ainda não é vista como algo relacionado ao cotidiano e ao comportamento individual de todos, como fechar a torneira ao escovar os dentes ou reduzir o consumo doméstico de energia elétrica.

Outro dado curioso apontado pela autora é que nas pesquisas realizadas (mesmo as mais recentes), os indivíduos são incapazes de identificar um problema ambiental em suas proximidades e circunvizinhança. Os problemas apontados são aqueles identificados pelos meios de comunicação como graves e grandiosos, a exemplo do desmatamento na Amazônia e a redução da vegetação nativa na Mata Atlântica.

Em Portugal, inquérito similar foi realizado no final da década de 1990, pelo Instituto de Ciências Sociais da Universidade de Lisboa, integrado ao programa OBSERVA (Ambiente, Sociedade e Opinião Pública). O inquérito é analisado por João Ferreira de Almeida (2000), que destaca alguns dos pontos centrais do levantamento, como a preocupação dos portugueses com os riscos ambientais, o item de maior repercussão conforme os dados estatísticos. Os riscos ambientais perdem apenas para a insegurança, que ocupa o primeiro lugar no rol das preocupações dos portugueses. Entre os itens que mais se destacam na escala da sondagem estão, por ordem de importância: (1) poluição em geral; (2) incêndios; (3) poluição dos rios e marés; (4) poluição do ar; (5) destruição da camada de ozônio; (6) tratamento de lixos; (7) contaminação alimentar; (8) alterações climáticas; (10) água potável; (11) catástrofes naturais; (12) desflorestação; (13) urbanização / industrialização;

No caso de Portugal, a relação entre ambiente, media e opinião pública também é analisada por Schmidt (2003). Conforme a estudiosa, habitualmente são considerados três níveis para enquadrar o debate sobre essa articulação: 
1. A função dos media na institucionalização/popularização dos problemas ambientais através da sua entrada na agenda como tema dominante;

2. Os problemas ambientais são uma construção dos media, (...) em que essa preocupação é produzida e o modo diferenciado como germina, privilegiando uns assuntos em detrimento de outros;

3. A interação entre os diversos agentes de produção mediática - fontes, jornalistas, programadores, arena institucional - e a respectiva intervenção em todo o processo comunicativo de formação da opinião pública (Schmidt, 2003, p.65).

Em linhas gerais, os estudos analisados reiteram as críticas e ressalvas sobre a relação dos media com a opinião pública, a exemplo de Sartori (1998), para quem o processo de formação da opinião pública na atualidade é essencialmente influenciado pela televisão. Quanto às pesquisas de opinião, o maior foco de críticas contemporaneamente concentra-se em sua utilização descontextualizada e interessada, principalmente pela e por meio da imprensa. A dinâmica que se estabelece a partir dessa divulgação seria a disputa pela "opinião do público, para que este abrace a opinião expressa ou publicada como opinião própria" (Brotas, 2003, p. 3). Essa visão é complementada por Garapon (2001, p. 91-93), para quem esse recurso selvagem à opinião pública é também pernicioso porque faz crer que, numa democracia, a opinião pública é o melhor juiz. Essa perspectiva analítica encontra respaldo na célebre crítica de Bourdieu (1982) em A opinião pública não existe, resumida em três postulados básicos, que ele considera premissas falsas: (a) a suposição de que todos podem ter uma opinião sobre determinado assunto; (b) o pressuposto de que estas opiniões se equivalem; (c) e de que existe um consenso sobre os problemas relevantes e perguntas que devem ser feitas. Tais problemas se aplicam mais exatamente à utilização das sondagens como instrutores da própria discussão pública e da legitimação política (Lopes, 2006). 


\subsection{Quais os impactos sociais das campanhas públicas} de esclarecimento sobre queimadas e incêndios?

Essa indagação é um dos eixos da pesquisa de Costa (2006) sobre as campanhas realizadas para conscientizar os agricultores familiares da Amazônia Legal, a fim de evitar queimadas indesejadas e reduzir os focos de incêndios. Apesar dos efeitos positivos dessas campanhas, a autora critica a concepção delas, baseadas no pressuposto da eficiência da transmissão unilateral de informações. Entretanto, esse pressuposto ignora toda a gama de conhecimentos tradicionais dessas populações sobre o fogo e os modos de controle das labaredas.

Portanto, se as campanhas levassem em conta o conhecimento tradicional das comunidades, seriam mais eficientes e menos autoritárias. A análise de Schmidt sobre essa temática também reforça o pressuposto de que há mais interesse dos media pela espetacularização do que pelo esclarecimento da população. O enquadramento, especialmente da televisão, é o da catástrofe. Acerca desse tópico, a estudiosa afirma que há três representações catastróficas que se complementam nas imagens mediáticas:

[...] Por um lado, os fogos florestais, um tipo de catástrofe que levou a tocar o âmago da complexidade dos fenômenos ambientais em todas as suas vertentes - técnicas, econômicas, sociais, políticas, históricas, naturais, culturais -, facto que em nenhuma das outras catástrofes acontecera. Será esta a primeira temática em que uma catástrofe é tratada em reflexão sobre o todo da sociedade portuguesa, mesmo que o resultado dessa reflexão seja algo inconclusivo. A outra catástrofe, a nuclear, situa-se no extremo oposto desta. $O$ tratamento que lhes é dado faz dela um acontecimento temível acima de qualquer outro, mas absolutamente estranho ao país e à sociedade portuguesa, como se em Portugal não existisse um reator nuclear nem houvesse à entrada dos seus rios internacionais grandes centrais nucleares espanholas, com capacidade de alcançarem em raios ínfimos de uma duas centenas de quilômetros a totalidade do território português. 
Se os fogos florestais constituem a catástrofe mais realista do ponto de vista ambiental, a catástrofe nuclear é a mais irrealista, apesar de ser a mais temida (Schmidt, 2003, p.321).

Pedro Almeida Vieira (2006), em seu livro "Portugal: O vermelho e o negro", critica a abordagem mediática que apresenta os incêndios florestais como tragédias inesperadas. Em sua avaliação, os fogos são, na realidade, consequência de erros crônicos e políticas equivocadas. Apesar de já serem percebidos pelos media e pela sociedade como um flagelo social, econômico e ambiental, o autor contesta o modo como ainda são representadas essas catástrofes que transformam Portugal "em um mar de chamas todos os verões".

\subsection{Como o terceiro setor contribuiu para o debate mediatizado} sobre ambiente e sociedade?

Esse questionamento é um dos eixos do problema investigado por Gonçalo Pereira Rosa (2006), em seu livro sobre a consolidação da QuerCus $^{4}$ como fonte de informação sobre ambiente em Portugal. Trata-se de um estudo paradigmático, que se tornou parâmetro e referência para a compreensão da inserção noticiosa das organizações não governamentais em Portugal e nos demais países da Comunidade dos Países de Língua Portuguesa. O estudo põe em relevo o papel das organizações ambientais do ambiente, sobretudo os efeitos da atuação delas sobre a produção jornalística. Para o autor, o crescimento da importância de movimentos cívicos "em representatividade e peso negocial nas sociedades contemporâneas modificou os relatos jornalísticos e promoveu a ascensão de fontes que a sociologia do jornalismo até então ignorara" (Pereira Rosa, 2006, p.8).

\footnotetext{
${ }^{4}$ A Quercus (Associação Nacional de Conservação da Natureza) é uma ong portuguesa, a mais importante do setor ambiental, fundada em 1985. Trata-se de um termo da botânica que abrange espécies como carvalhos, azinheiras e sobreiros, as árvores características dos ecossistemas florestais mais evoluídos que cobriam o país.
} 
Ao analisar o caso da Quercus em Portugal, o autor recorreu a outros estudos realizados na Europa e nos Estados Unidos sobre as consequências da relação entre as organizações não governamentais do ambiente (ONGAs) e os media. A conclusão do autor é que tanto as ONGAs interferiram no modo de se fazer jornalismo sobre ambiente, como elas próprias também foram afetadas por essa intervenção, sobretudo em decorrência das estratégias de aproximação dos jornalistas e adequação aos critérios de noticiabilidade e aos valores-notícia.

As ONGAs, por sua vez, causaram impactos significativos no esquema convencional que orientava a relação dos media com as fontes, até então, de natureza predominantemente oficial. No modelo convencional, as instituições públicas funcionavam como armazéns de notícias, sempre prontas a abastecer os jornalistas com dados, estatísticas e declarações.

A dificuldade inicial das entidades ambientalistas, conforme destaca Pereira Rosa, estava em romper o estereótipo de movimentos de contestação, sempre dispostos a disparar críticas contra os governantes e gerar polêmica, na maioria das vezes, sem dados e informações de ordem objetiva. Assim, essas entidades eram procuradas pelos jornalistas apenas quando eles buscavam esse tipo de enquadramento. Essa relação esporádica e estigmatizada prejudicava os movimentos, visto que sua imagem era associada geralmente a casos específicos e suas declarações eram encaixadas em matérias jornalísticas já pré-formatadas, com o objetivo de acirrar os conflitos, numa perspectiva descontextualizada, que apontava, na maioria das vezes, para os comportamentos e fatos desviantes.

As entidades ambientalistas passaram, então, a investir em estrutura, recursos e estratégias para modificar a relação com os media e com os jornalistas e, assim, conseguirem intervir na imagem delas projetada para a opinião pública. Nesse processo, as entidades ambientalistas passaram não só a fornecer informações em consonância com os pacotes 
mediáticos, mas também a exercer controle sobre a fase pós-cobertura, como estratégia de vigilância sobre os significados das notícias, visto que a divulgação delas produz efeitos imediatos na imagem da organização. Como explica o autor, as fontes preocupam-se em exercer controle sobre esse significado das notícias, "porque a publicação produzirá efeitos na organização a que estão vinculadas" (PEREIRA ROSA, 2006, p.39).

Essa estratégia é usada como meio preventivo, visto que os efeitos maléficos após a divulgação das notícias são praticamente irreversíveis, mesmo que haja direito de resposta. Assim, deduz-se que a visibilidade aos movimentos ambientalistas decorre de uma combinação de fatores. Além de atuarem em áreas de notória deficiência do Estado, as ONGAs, passaram a ter domínio sobre o ciclo de produção das notícias e estabeleceram uma rede de relacionamento com os media. Segundo Pereira Rosa (2006, p.74),

o conhecimento do ciclo noticioso, o relacionamento pessoal de alguns dirigentes com jornalistas, a capacidade de reagir rapidamente a um acontecimento e a facilidade de aceder a informação técnica e descodificá-la para a linguagem jornalística são os recursos que tornam os dirigentes de organizações não-governamentais do ambiente fontes potenciais de informação (Pereira Rosa, 2006, p.74). ${ }^{5}$

As entidades tentam manter-se em evidência, ao alimentarem notícias, gerarem controvérsias e demandas para que seus aliados e oponentes também se pronunciem sobre os temas discutidos. Outra estratégia é a polarização com as instituições governamentais. Enquanto os representantes do Governo tentam fixar suas ações, numa perspectiva positiva, as entidades não governamentais ficam de plantão, para apontar lacunas em todas as ações governamentais (Pereira Rosa, 2006).

${ }^{5} \mathrm{O}$ autor chega a essa conclusão com base em entrevista com um dos dirigentes da Quercus, Francisco Ferreira. 
Além de se estabelecerem como fontes credíveis e recorrentes para as instituições jornalísticas, como foi destacado na análise do tópico anterior, as organizações não governamentais voltadas para a defesa do ambiente desenvolveram amplo potencial para ações políticas e de intervenção crítica em relação ao planejamento, execução e avaliação de políticas públicas. Tanto no Brasil como em Portugal existem estudos que destacam esse potencial de intervenção, apontado como responsável pelo novo desenho de ações políticas voltadas para o campo ambiental. Essa intervenção levou as instituições oficiais a adotarem procedimentos mais transparentes, em função da cobrança e da vigilância permanente das instituições ecológicas.

Born (2005) investiga especificamente esse ponto, no âmbito da realidade brasileira. Apesar dos estereótipos negativos e da fragilidade institucional existente na maioria delas, as ONGAs têm tido um papel cada vez maior e mais efetivo em políticas públicas e geração de iniciativas (Born, 2005, p. 107). Para o autor, a partir da perspectiva funcional, essas entidades passaram a exercer diferentes papéis na sociedade e na esfera política, os quais se complementam e reforçam seu poder de intervenção nas políticas públicas. As funções elencadas pelo estudioso são: (a) denúncia e revelação de problemas ambientais; (b) atuação em prol da educação ambiental e da mobilização social; (c) assessoria jurídica para a promoção de direitos ambientais; (d) pesquisa e difusão do conhecimento ecológico; (e) monitoramento e fiscalização de obras públicas que causam impacto ambiental; (e) implementação de projetos de sustentabilidade; (f) assessoria, disseminação e multiplicação de ideias e práticas sustentáveis; (f) formação de capital humano para as redes e projetos de sustentabilidade.

Em suma, podemos inferir que o somatório de todas essas forças é que contribuiu para ampliar a repercussão dos temas ambientais nos media tanto no Brasil como em Portugal, de acordo com as peculiaridades 
de cada país. Mais uma vez, portanto, podemos recorrer aos pressupostos da Teoria Multifactorial da Notícia (Sousa, 2000).

\section{Considerações finais}

A análise tentou mostrar de que forma a mediatização do ambiente reflete a trajetória das ideias ecológicas pelo viés da visibilidade propiciada pela janela hermenêutica dos media. Em termos mais específicos, a pesquisa mostra como os media atuaram na formação de uma cultura ambiental nas últimas décadas nos dois países, principalmente se considerarmos a inserção social das questões socioambientais nas pautas culturais, a partir da força da programação televisiva. A eficácia simbólica dos media passou a exercer um efeito farol na formação da opinião pública, inclusive com a adesão do terceiro setor à lógica mediática, com a adequação dos arranjos discursivos desses atores ao enquadramento mediático. É todo esse processo que se caracteriza como produção social da visibilidade ambiental, a partir do recorte analítico proposto.

É necessário ressaltar ainda a natureza ambígua da mediatização. Ao mesmo tempo que se trata de um processo social que permite e amplia a visibilidade pública das temáticas, atores, fatores e questões relacionadas ao ambiente, também pode direcionar a cobertura para determinados aspectos que nem sempre favorecem a conscientização pública e a compreensão do cidadão. Isso pode ocorrer, por exemplo, quando as lógicas mediáticas submetem a agenda ambiental às abordagens sensacionalistas, à espetacularização, à fragmentação e às emissões episódicas e descontextualizadas.

Ademais, há momentos em que parece que todos os veículos de comunicação são favoráveis às reivindicações ambientais, mas também há situações que parecem testar a credibilidade e a força dos movimentos. Pereira Rosa (2006, p.136) complementa que essa ambiguidade pode se 
manifestar também quando os media exigem uma mensagem mais simplificada, mas consumível e, portanto, traindo de alguma forma a complexidade do movimento que a proferia. Por outro lado, o funcionamento de um noticiário televisivo não se compadece com movimentos com diversos pontos de vista. Exige porta-vozes, rostos aceitáveis perante as câmaras, fluidez de discurso e sobretudo continuidade... (grifos originais).

Cabe situar, contudo, do ponto de vista sociológico, que a ambiguidade é uma das marcas da dinâmica sociocultural e política, conforme analisa Max Weber em Economia e Sociedade. O cálculo das transações sociais e políticas envolve sempre perdas e ganhos, possibilidades e limites, progressos e recuos, isto é, em toda lógica de transformação social e cultural pode haver benefícios para determinados segmentos da sociedade e descontentamento para outros. Da mesma forma, a ambiguidade faz parte da lógica dos pacotes interpretativos, ou seja, trata-se de um elemento constituinte da própria mediatização, uma espécie de template semântico para dirigir a atenção do público, conforme argumenta Castells (1999) ao tratar da força simbólica que os enquadramentos selecionados pelos media exercem na formação e difusão da opinião pública.

Apesar do caráter ambíguo da mediatização, outra constatação que deve ser destacada é o pressuposto que permeia a maioria dos estudos analisados, no que se refere à globalização do ambiente e à formação das redes de entidades voltadas para os diferentes aspectos do ambiente. Esse fenômeno é recorrentemente mencionado nos estudos analisados e chega a ser apontado como a inspiração para a constituição de uma agenda ambiental nacional, tanto no Brasil como em Portugal, países que apresentam em comum um longo período de omissão em relação à formulação e execução de políticas públicas eficazes na área ambiental. 
Sociologias, Porto Alegre, ano 15, no 33, mai./ago. 2013, p. 318-345

\section{Referências}

ACOT, P. História da ecologia. Rio de Janeiro: Campos, 1990.

AGUIAR, S. Análise dos estudos sobre jornalismo ambiental: primeiras incursões. In: 9o Encontro Nacional dos Pesquisadores em Jornalismo, 2011, Rio de Janeiro. Anais... Brasília: SBPJor, 2011.

ARENDT, H. A condição humana . Rio de Janeiro: Forense, 1983.

ALMEIDA, J. F. de. Os portugueses e o ambiente: I inquérito Nacional às representações e práticas dos portugueses sobre o ambiente. Oeiras: Celta Editora, 2000.

ALONSO, A; COSTA, V. Por uma Sociologia dos Conflitos Ambientais no Brasil. Paper apresentado no Encontro do Grupo Meio Ambiente e Desenvolvimento da Clacso. Rio de Janeiro, 22 e 23 de novembro de 2000.

BARDIN, L. Análise de conteúdo. Lisboa: Edições 70, 1977.

BARROS, F. L. de. Ambientalismo, globalização e novos atores sociais. Sociedade e Estado. Brasília, v.21, n.1, p.121-137, jan./jun. 1996.

BARROS, A. T.; SOUSA, J. P. Jornalismo e ambiente. Porto: Edições Universidade Fernando Pessoa, 2010.

BOBBIO, N. A era dos direitos. Rio de Janeiro: Campus, 1992.

BORN, R. H. Meio ambiente e terceiro setor. In: TRIGUEIRO, André (Coord.). Meio ambiente no século XXI. Campinas: Autores Associados, p. 106-121, 2005.

BOURDIEU, P. A opinião pública não existe. In: THIOLLENT, Michel J. M. Crítica metodológica, investigação social e enquete operária. 3. ed. São Paulo: Polis, 1982.

BRAGA, J. L. Mediatização como processo interacional de referência. Texto apresentado no Grupo de Trabalho Comunicação e Sociabilidade, do XV Encontro Anual da Associação dos Programas de Pós-Graduação em Comunicação (Compós), na Unesp/Bauru, São Paulo, em junho de 2006.

BRAGA, J. L. A sociedade enfrenta sua mídia: dispositivos sociais de crítica mediática. São Paulo, Editora Paulus, 2006b.

CASTELLS, M. A sociedade em rede. São Paulo: Paz e Terra, 1999.

CLARKE, M. (2001). Formulating the problem. Oxford.

COSTA, L. M. Comunicação e meio ambiente: análise das campanhas de prevenção a incêndios florestais na Amazônia. Belém: Núcleo de Altos Estudos Amazônicos, 2006. 
CRESPO, S. Uma visão sobre a evolução da consciência ambiental no Brasil nos anos 1990. In: TRIGUEIRO, André (Coord.). Meio ambiente no século XXI. Campinas: Autores Associados, p.59-74, 2005

DENCKER, A. F. \& KUNSCH, M. M. K. (1996). Comunicação e meio ambiente. São Paulo: Intercom, 1996.

FERREIRA, L. da C. Idéias para uma sociologia da questão ambiental no Brasil. São Paulo: Anna Blume, 2006.

FIGUEIREDO, V. Produção social da tecnologia. São Paulo: EPU, 1989.

FREITAS, H. de S. Jornalismo de ambiente em Portugal: espécie em vias de extinção? Jornal dos Jornalistas, Lisboa, jan./mar, p.30-40, 2007. Disponível em: http://www.clubedejornalistas.pt/admin/Portal/LinkClick.aspx?tabid=925\&table $=$ Links\&field $=$ ItemID\&id $=529 \&$ link $=J J 29 \_$Ambiente.pdf.

GARAPON, A. O juiz e a democracia: o guardião das promessas. 2. ed. Rio de Janeiro: Revan, 2001.

GARCIA, C. M. Rio-92: desenvolvimento e meio ambiente. In: VELLOSO, J. P. dos Reis (Org.). A Ecologia e o novo padrão de desenvolvimento no Brasil. São Paulo: Nobel, p.17-18, 1992.

GARCIA, R. Sobre a Terra: Um guia para quem lê e escreve sobre o ambiente. Lisboa: Público, 2004.

GERBNER, G. et al. Growing up with television: the cultivation perspective. In: BRYANT, J.; ZILLMANN, D. (Eds.). Media Effects: Advances in Theory and Research. Hillsdale: Laurence Erlbaum Associates, p.17-41, 1994.

GITLIN, T. The whole world is watching. Califórnia: University of California Press, 1980.

GOFFMAN, E. Frame Analysis: an essay on the organization of experience. Cambridge: Havard University Press, 1974.

HABERMAS, J. Direito e democracia: entre facticidade e validade. Rio de Janeiro: Tempo Brasileiro, 1997.

HOBSBAWN, Eric. A era dos extremos. São Paulo: Companhia das Letras, 1995.

LOPES, M. A.; GASPAR, P. O acesso à informação e participação em matéria de ambiente. Lisboa: Instituto de Promoção Ambiental, 1993.

MOTTA, L. G. et al. Os transgênicos na grande imprensa: uma análise de conteúdo. In: NASCIMENTO, Elimar Pinheiro do; VIANNA, João Nildo de Souza. Economia, meio ambiente e comunicação. Rio de Janeiro: Garamond, p.11-38, 2006. 
OLIVEIRA, M.T.C. O jornalismo científico na abordagem das questões ambientais. São Paulo: Associação Brasileira de Jornalismo Científico, 1991.

PEREIRA ROSA, G. A Quercus nas Notícias. Porto: Porto Editora, 2006.

SARTORI, G. La opinión teledirigida. Claves de la razón practica. Enero/feb., n. 79, 1998.

SCHMIDT, L. Sociologia do ambiente: genealogia de uma dupla emergência. Análise Social, Lisboa, v.34, n.150, p.175-210, out./dez, 1999.

SCHMIDT, L. Ambiente no ecrã: emissões e demissões do serviço público televisivo. Lisboa: Imprensa de Ciências Sociais, 2003.

Imprensa de Ciências Sociais.

SOUSA, J. P. As notícias e seus efeitos: as teorias do jornalismo e dos efeitos sociais dos medias jornalísticos. Coimbra: Minerva-Coimbra, 2000.

TRIGUEIRO, A. Meio ambiente na idade mídia. In: TRIGUEIRO, André (Coord.). Meio ambiente no século XXI. Campinas: Autores Associados, p.75-90, 2005.

VIEIRA, P. A. Portugal: O vermelho e o negro. Lisboa: Dom Quixote, 2006.

VIOLA, E. J.; LEIS, H. R. O ambientalismo multissetorial no Brasil para além da Rio-92: o desafio de uma estratégia globalista viável. In: VIOLA, Eduardo J. et al. Meio Ambiente Desenvolvimento e Cidadania: desafios para as ciências sociais. São Paulo: Cortez, p.134-160, 1995.

YEARLEY, S. A causa verde: uma sociologia das questões ecológicas. Oeiras: Celta, 1992.

Recebido em: 14/12/2012

Aceite final: 23/04/2013 